\title{
REVIEWS.
}

\section{URINARY INFECTIONS}

\author{
By Clifford Morson, O.B.E., F.R.C.S.
}

(Pocket Monographs on Practical Medicine.

Price 2/6. John Bale, Sons \& Danielsson, Ltd., London, 1933.)

A further addition to the series of Pocket Monographs on Practical Medicine, written by such a well-known authority on urinary diseases as Mr. Clifford Morson, is bound to command great attention. Mr. Morson has had no easy task in compressing into a space of seventy-three-and-a-half small pages the outlines of what has become a very vast subject, the literature of which has grown enormously in the last decade. It is no small tribute to him to say that he has succeeded admirably in his purpose. The essential principles of the subject are extremely well portrayed in very simple language. We are, however, a little surprised that Mr. Clifford Morson has not emphasized the intensive alkaline treatment which has been worked out by Osman in acute infections due to Bacillus coli communis. This is not the place to enter into a discussion on the subject, but we think that in the treatment of this condition more emphasis should have been made on this aspect, as vaccines and drugs-other than alkalies-have proved particularly disappointing. We hope that in another edition this omission will be repaired. Also we are surprised that Mr. Clifford Morson treats the Bacillus coli communis with such scant respect as to call it by different names. Without being pedantic in the matter, we do not see why this well-known organism should, in places, receive the name of "Colon Bacillus", nor do we consider that the term "Colon Bacilluria" is one that should be used. It is neither pathologically nor grammatically correct. While it is admitted that these terms are used colloquially, we feel that they should not be used in literature. These, however, are minor blemishes which no doubt will be corrected in a subsequent edition.

We can thoroughly recommend this book as an interesting, concise and abridged account of the several diseases which are included under this heading.

\section{A SHORT HISTORY OF OPHTHALMOLOGY}

By Arnold Sorsby, M.D., F.R.C.S.

John Bale, Sons \& Danielsson, Ltd.

$$
\text { Price 3/6. }
$$

The lure of medical history has recently revived interest in the subject and this has shewn how much value there may be for the thoughtful observer in a consideration of the theories and practice of the past. This short history of ophthalmology comes from a practised writer with a wide knowledge of the subject based largely on personal research. It forms a most readable and thorough review of ophthalmology as far back as can be traced, and its interest should make it very attractive to a circle much larger than that of the specialty whose history it outlines. The general makeup of the book and the illustrations provide the best use of the historical material which Mr. Sorsby so ably presents.

\section{BROMPTON HOSPITAL REPORTS}

Vol. II., 1933.

Gale \& Polden, Ltd., Aldershot. Price 2/6.

This volume is a collection of papers which have been published in various medical journals during 1933 by members of the staff of the Brompton Hospital. Many of the articles are well worth preserving in this more permanent form and they are evidence of the vitality, progressiveness and varied interests of the staff of this most famous Institution. In addition to several articles on different aspects of the question of pulmonary tuberculosis, bronchiectasis and intrathoracic new growths, there is an interesting account of that versatile and original physician, Nicolas Culpeper, by Dr. Cecil Wall, and a most stimulating address on "The Influence of the Discovery of the Tubercle Bacillus by Robert Koch on Medicine," from the pen of Dr. R. A. Young. 